Article

\title{
Determinants of the Adoption of Sustainable Intensification in Southern African Farming Systems: A Meta-Analysis
}

\author{
Qian Guo, Oreoluwa Ola ${ }^{\mathbb{D}}$ and Emmanuel O. Benjamin * \\ Department of Governance in International Agribusiness and Department of Agricultural Production and \\ Resource Economics, Technical University of Munich (TUM), 85354 Freising, Germany; \\ ga87sip@mytum.de (Q.G.); oreoluwa.ola@tum.de (O.O.) \\ * Correspondence: emmanuel.benjamin@tum.de; Tel.:+498161712772
}

Received: 22 January 2020; Accepted: 15 April 2020; Published: 17 April 2020

check for updates

\begin{abstract}
Climate change and environmental degradation are major threats to sustainable agricultural development in Southern Africa. Thus, the concept of sustainable intensification (SI) has become an important topic among researchers and policymakers in the region over the last three decades. SI involves getting more output from less input using practices such as agroforestry, organic fertilizer, sustainable water management, among others. A comprehensive review of the literature on adoption of SI in the region identified nine relevant drivers of adoption of SI among (smallholder) farmers. These drivers include (i) age, (ii) size of arable land, (iii) education, (iv) extension services, (v) gender, (vi) household size, (vii) income, (viii) membership in a farming organization and (ix) access to credit. We present the results of a meta-analysis of 21 papers on the impact of these determinants on SI adoption among (smallholder) farmers in the Southern African Development Community (SADC) using random-effects estimation techniques for the true effect size. While our results suggest that variables such as extension services, education, age, and household size may influence the adoption of SI in SADC, factors such as access to credit are also of great importance. Decision-makers should, therefore, concentrate efforts on these factors in promoting SI across the SADC. This includes increasing the efficiency of public extension service, as well as the involvement of the private sector in extension services. Furthermore, both public and private agriculture financing models should consider sustainability indicators in their assessment process.
\end{abstract}

Keywords: climate change; sustainable intensification (SI); adoption; smallholder; meta-analysis; random-effect model; effect size; Southern Africa Development Community (SADC)

\section{Introduction}

Meeting the United Nations Sustainable Development Goal of eradicating hunger and guaranteeing food security by 2050 might entail a $69-110 \%$ increase in current global food production [1,2]. Similarly, the global population is estimated to increase from seven to nine billion by mid-century [3]. These projections put a spotlight on agriculture, as food production must increase to meet rising food demand. However, meeting these challenges is complicated by the fact that several current agricultural practices degrade the environment; contributing about 19-29\% of current global greenhouse gas (GHG) emissions, the majority of which comes from land clearing and intensive farming needed to increase crop production [1,4]. This has led to calls for a shift in current agricultural practices towards cultivation systems that accommodate both sustainability and increased productivity [3]. Several terminologically different, but conceptually similar production systems have been proposed to achieve this goal. These systems include climate-smart agriculture (CSA), ecological intensification, conservation agriculture and sustainable Intensification (SI). 
The Montpellier Panel [5] define SI as agricultural practices that result in higher outputs from the efficient use of available inputs, while simultaneously reducing environmental damage, building resilience and improving environmental services. According to Garnett et al. [6] four principles support SI. One, increasing food production. Two, increasing production through higher yields, not land expansion. Three, equally prioritizing environmental sustainability and increased productivity to achieve food security. Four, a process that requires rigorous assessment of various sustainability approaches within different social and institutional contexts to ascertain the merits of each approach. Common agricultural SI practices include organic fertilizer use, improved crop cultivars, soil and water conservation methods, cereal-legume intercropping, crop rotation, contour ploughing, leguminous trees, and agroforestry $[7,8]$.

In sub-Saharan Africa (SSA), agricultural production per capita still lags behind production per capita in Asia and Latin America [9]. While farm yield has increased in previous years, these gains are typically from land expansion [10]. Opening up new arable lands, however, faces competition from other human activities [9]. High rates of food insecurity and projected population increases on the continent point to the need to intensify further agricultural production [11]. How to intensify agriculture, without the accompanying environmental degradation and increases in GHG emissions remains a challenge. SI has been touted as a solution to these challenges [12,13].

Pretty et al. [9] documents several benefits emerging from various projects that deploy SI practices in SSA countries between the 1990s and 2000s. These include, on average a 2.13 fold increase in yield, improvements in soil carbon content and a $94.5 \%$ reduction in pesticide use. Several studies have also demonstrated the superiority of adopting SI practices to conventional agricultural practices in improving crop productivity and food security $[14,15]$. The fact that only direct benefits of adopting SI practices are often reported may also underestimate the true effect of SI. For example, Benjamin et al. $[16,17]$ found that agroforestry payment for ecosystem schemes could promote financial inclusion among smallholder farmers and economically empower female smallholders. Benjamin and Sauer [18] also found that these schemes tend to be cost-effective for developers introducing SI practices and farmers alike.

Despite the benefits of SI, adoption of SI practices remains very low among farmers and pastoralists across the SSA sub-region $[9,11,19]$. This is despite several campaigns and initiatives aimed at promoting the adoption of SI practices in SSA [10]. Farmers must perceive adequate welfare gains from SI uptake before choosing to adopt SI [20]. However, tradeoffs between economic productivity and sustainability often prolong gains from adopting SI [21]. Consequently, incentivized interventions, e.g., financial, behavioral, and institutional, are often needed to ensure the uptake of SI practices and promote sustainable agriculture [22,23]. Designing interventions to encourage sustainable agriculture or identifying specific target groups involves the identification and a better understanding of the factors driving the adoption of SI practices.

In this study, we address this issue. We focus specifically on agricultural systems in the Southern African Development Community (SADC). The region comprises Angola, Botswana, the Democratic Republic of Congo, Lesotho, Madagascar, Malawi, Mauritius, Mozambique, Namibia, Seychelles, South Africa, Swaziland, United Republic of Tanzania, Zambia, and Zimbabwe. Agricultural production increases in Africa are less pronounced in SADC compared to Western or Northern Africa [9]. Moreover, climatic conditions in the SADC are mostly semi-arid or sub-humid climates and under threat from climate change [24]. The threats posed by climate change in the SADC are related to erratic rainfall patterns, changes in temperature, and extreme weather conditions such as reoccurring droughts and floods [25]. This exposes arable lands in the region to environmental degradation, biodiversity losses and unsustainable natural resource management; further threatening the livelihoods of smallholders in SADC unless concrete measures are taken to address the situation.

Given the potential benefits of adopting SI practices, the question that arises is: What are the essential drivers or determinants of SI among smallholder farmers in regions most vulnerable to climate change such as the SADC? Several empirical studies have investigated the determinants of 
adoption of SI practices. They have focused on various human capital assets, farm assets, institutional factors, risks and economic factors, and climatic conditions that drive SI adoption.

We aim to collate results from empirical studies examining SI adoption in SADC to obtain a true effect size that depicts the importance of various drivers of SI adoption. This provides insights into the direction of the relationship between different human, social, economic and institutional capital factors, and adoption of SI practices. From a policy perspective, we provide information useful to decision-makers interested in designing policy initiatives or intervention measures that encourage the adoption of SI practices in the SADC.

To the best of our knowledge, this is the first study to use meta-analytic methods to estimate the true effect size of the determinants or drivers of SI in SADC. The random-effects models, such as the DerSimonian-Laird (DL) model, Maximum-likelihood (ML) model, Restricted Maximum-likelihood (REML) model, Profile-likelihood (PL) model, and Permutations (PE) model were used for this meta-analysis. The standardization of the effect size of the studies to ensure the evaluation of heterogeneity followed uniformity. This resulted in between-study variance and its mitigation in preparation for the meta-analysis. Our results, which are not only based on statistical significance but also the precision of estimation, indicate that access to credit, arable land, education, extension, gender, and household size mainly drive SI adoption in SADC.

The rest of the paper is structured as follows. Section 2 outlines the materials and methods uses for the meta-analysis. Section 3 presents the results of the meta-analysis. Section 4 opens up some insightful discussion with regards to the results. Section 5 concludes.

\section{Materials and Methods}

\subsection{Criteria for Selecting Studies}

Choice of Studies: One of the first steps of the literature review in this meta-analysis was the retrieval and selection of studies [26]. Only studies that investigated determinants of smallholder's decisions to adopt SI in SADC and studies that were written in English were considered for this study. Furthermore, these studies must have reported quantitative data sufficient for computing weighted average effect sizes.

\subsection{Search Method and Strategy}

We searched the following online social science database from September 2018 through March 2019: Google Scholar, PubMed, ISI Web of Science, ResearchGate, and ScienceDirect. The following keywords and descriptors were used as search criteria namely: 'sustainable intensification agriculture - SIA,' 'Sustainable Intensification Practice - SIP,' 'determinants, improved cultivar,' 'cereal-legume intercropping,' 'crop rotation,' 'organic fertilizer,' 'contour plough,' 'leguminous trees, ' 'agroforestry,' 'soil conservation,' and 'pest management.' The search was extended to the reference list of the relevant articles to ensure that relevant studies were not neglected unintentionally.

\subsection{Data Collection and Analysis}

The author(s) conducted the article selection process by initially screening the articles that matched the selection criteria by title and abstract. This was followed by data extraction from the studies that met the selection criteria. The data extracted from each article are as follows: title, author(s), study area, type of SI, characteristics of intervention(s), and outcome data. The outcome data extracted from each article included coefficients and standard errors from a logistic rather than probit regression as it would be impossible to find an effect size measure that simultaneously suits both methodologies. If the outcome data were missing or unclear, then the authors excluded such studies.

Logistic and probit regression are models often used in the adoption papers. The reason logistic and probit regression are widely used in studies investigating the determinants of technology adoption such as SI is because dependent variables representing technology adoption are often categorical [27]. In this 
case, categorical means a value of one for adopting a specific intervention and zero for non-adoption. There were 112 studies meeting the above requirements, among which 50 studies presented their results using logistic regression. There were no duplicate studies within these 50 studies. However, 15 of the 50 studies presented only marginal effect instead of the odds ratio (OR) and were dropped. Among the remaining 35 studies, 14 did not provide standard errors of coefficients and were removed from the database. From the remaining 21 studies, we extracted 33 estimates because some studies analyzed more than one SIPs. We illustrate this process in Figure 1.

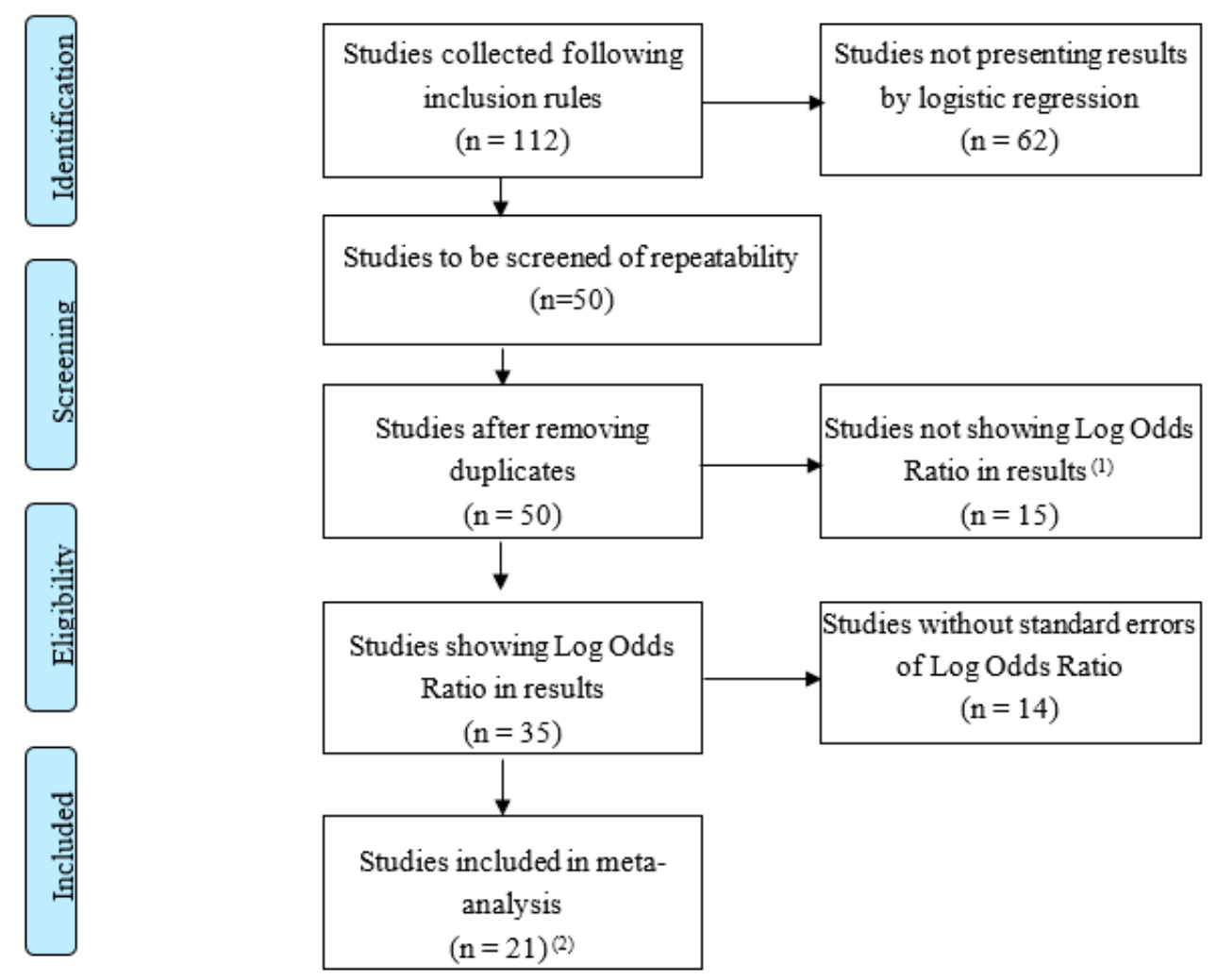

Figure 1. Flow diagram of literature review. (1) Some logistic regression coefficients were presents not in the form of log OR but marginal effect. (2) The included 21 studies contain 33 study results, as some of them contain more than one results in one paper. Source: Own illustration modified from the PRISMA flow diagram (2009).

\section{Method of Meta-analysis}

Since the purpose of a meta-analysis is to combine study results, effect size statistics (regression) are tools for transforming different forms of results into a common form, to compute the overall magnitude of a phenomenon across primary studies. In a meta-analysis, the overall effect size is a quantitative measure of the influence of a variable or factor on the outcome of interest [28]. It could be interpreted as an index to quantify the relationship between an independent variable and a dependent variable in a function. However, it is important that a common measure is calculated for different studies and then combined into an overall summary. Given that units of measurements included in primary study results are often different, a standardized effect size is more appropriate. In our case, the standardized effect size was derived from the association-based family, $r$, which measures the size of variation between two (or more) variables observed in the same sample or different samples [29]. Using the association-based family, $r$, estimation, we opted for the estimation of the odds ratio as this is appropriate for logistic regression [29].

The fixed-effect model and random-effects model are the two models commonly used in meta-analysis in computing the weighted average effect sizes [30]. The fixed-effect model assumes 
the true effect to be the same (i.e. homogeneous) across studies, and the weighted average effect size is an estimate of this true effect size. In contrast, the random-effects model assumes distribution and variance in the true effect size across studies. A random-effects model is appropriate if (a) it is unlikely that all the studies are practically similar and (b) the research goal is to compute a weighted mean of true effect sizes, which would then be generalized for the entire population. In most cases, homogeneity has been the exception rather than the rule, and some degree of true effect variability between studies is to be expected [31]. For instance, experiments or projects on SI in SSA are often conducted in different locations, recruit participants with different standards, or adopt various SIPs. It is, therefore, plausible to assume a distribution of true effect sizes for each determinant. Thus, in this study, we settled for the random effect models of estimating the effect sizes. The weighted average effect computed by the random-effects model is an estimate of the weighted mean of a distribution of true effect sizes. The equation for the random-effects model [32] can be written as:

$$
y_{i}=\mu_{R E}+\varepsilon_{i}+\delta_{i}
$$

where $y_{i}$ is the observed effect in the study $i$; $\mu_{R E}$ is the common true effect; $\varepsilon_{i} \sim N\left(0, v_{i}\right)$, and $v_{i}$ is the within-study variance in the study $i$. Meanwhile, $\delta_{i} \sim N\left(0, \tau^{2}\right), \tau^{2}$ represents the between-study variance. In the random-effects model, we assume the observed variation: $\operatorname{Var}\left(y_{i}\right)$, is caused by within-study and between-study variance, illustrated in Equation (2) as:

$$
\operatorname{Var}_{R E}\left(y_{i}\right)=v_{i}+\tau^{2}
$$

The weighting method for the estimating of effect size computed by the random-effects model, $\hat{\mu}_{R E}$, [33] is calculated as:

$$
\hat{\mu}_{R E}=\frac{\sum y_{i} w_{i, R E}}{\sum w_{i, R E}} \quad \text { where } w_{i}=\frac{1}{v_{i}+\tau^{2}}
$$

where $y_{i}$ is the estimated effect size for study $i$, and $w_{i}$ is the weight for study $i$. It is important to note that when there is between-study variance, the random-effect model gives lower weights to study $i$ and wider 95\% confidence intervals (CIs) [34]. Another important thing to note from the Equations above is the central role that between-study variance, $\tau^{2}$, plays in the estimation of the overall effect using the random-effects model. This estimation of between-study variance $\tau^{2}$ can be done using the DerSimonian-Laird (DL) model, Maximum-likelihood (ML) model, Restricted Maximum-likelihood (REML) model, and the Profile-likelihood (PL) model [32]. The Stata commands metaan and metan both can be used for meta-analysis given the pre-calculated effect estimates extracted from included primary studies with the latter providing statistical significance level for the estimated overall effect size. In this study, we shall place some emphasis on the REML model because we have dichotomous outcome data and there may exist large between-study variance $\left(\tau^{2}\right)$. As for the estimation method of CI for between-study variance, i.e., the precision of effect, the PL method performs better than the Wald-type method in terms of coverage probability [35-38]. The objective of our meta-analysis was to find the estimated overall effect size for each of the determinants above. The outcome should be statistically significant and precise. Since the precision value, i.e., $\mathrm{CI}$ is derived from the equation that generates the P-value, there is a relationship between both values $[39,40]$. If the value of zero is reported at the $95 \% \mathrm{CI}$, then the null hypothesis (effect size $=0$ ) is rejected, and this estimate is statistically significant at the 5 per cent level $[41,42]$. To this end, only statistically significant estimates close to the true value are relevant. Table 1 below provides an overview of the estimation methodology using the statistical tool Stata. 
Table 1. Overview of Stata Commands metan and metaan for aggregate data meta-analysis.

\begin{tabular}{cccc}
\hline Stata Command & $\begin{array}{c}\text { Estimation Methods for } \\
\boldsymbol{\tau}^{2}\end{array}$ & $\begin{array}{c}\text { Estimation Methods for } \\
\text { CI of } \tau^{2}\end{array}$ & $\begin{array}{c}\text { Significance Test } \\
\text { (P Value) for } \hat{\mu}^{\text {(2) }}\end{array}$ \\
\hline metan & DL & Wald-type & Available \\
metaan & DL, ML, REML & Wald-type, PL & Not Available \\
\hline
\end{tabular}

Note: (1) denotes between-study variance and (2) denotes estimated overall effect size. Source: Authors illustration modified from Kontopantelis \& Reeves (2010) and Harris \& Bradburn (2008).

\section{Heterogeneity}

The between-study variance stemming from differences in populations, interventions, outcomes or follow-up times is called heterogeneity [33,34]. If the studies are very dissimilar on these factors, it may be preferable not to pool the results [43]. Heterogeneities among primary study results affect the true effect. In this paper, the included primary study results have some similar characteristics, but also contain potential sources of heterogeneity. Similar characteristics shared by the primary studies include smallholders as participants living in the SADC member states, SI as trial interventions, and multivariate logistic regression equations as study outcomes containing regression coefficients and their standard errors. On the other hand, there are several potential sources of heterogeneity, given that the domain of value for some variables differs between studies. For instance, the study by Ngwira et al. [44] on the adoption of conservation agriculture measured education as an ordinal variable $(2=$ secondary level, $1=$ primary, and $0=$ illiterate), while Chompolola and Kaonga [45] measured education in years of schooling. Furthermore, other factors such as duration of the experiments, the disparity in the number of independent variables measured across primary studies, the reliability of outcome measures, as well as the correlation between independent variables, may affect the accuracy of the estimation of the effects of determinants. Thus, it is necessary also to undertake a heterogeneity test to evaluate the extent of between-study variance. There are three default heterogeneity tests provided by the Stata command metan namely: Cochrane's $Q, I^{2}$, and $\tau^{2}$. In this study, we restricted ourselves to $I^{2}$, which is the percentage of the total variability in a set of effect sizes due to true heterogeneity, i.e., between-study variability [46]. We cannot use $\tau^{2}$ to compare the absolute value of heterogeneity across determinants, as most determinants are in different metrics. Higgins and Thompson [33] classify the values of $I^{2}$ as ranging from low $(<25 \%)$, moderate $\left(25 \% \leq I^{2}<50 \%\right)$, high $\left(50 \% \leq I^{2}<75 \%\right)$ to considerably high $\left(I^{2} \geq 75 \%\right)$. If the value of $I^{2}$ is low then there is limited between-study variance. Therefore, further analysis to explore the cause through subgroup analysis is not necessary. However, if the value of $I^{2}$ is large, then subgroup analysis is essential. It can also help reduce the between-study variance. In this study, we proposed a subgroup analysis based on effect size and outliers. This process eliminated the outliers, i.e., dropping single effect sizes far away from the estimated overall effect size, to make the result more consistent. Such outlier observed in our sample may be due to variability in the measurement or experimental error. In this paper, values falling out of a distance of half of the width of the $95 \%$ CI of estimated overall effect size are outliers. Therefore, it resulted in two subgroups with the single effect sizes within this interval termed as more consistent, while single effect sizes out of this interval were less consistent.

\section{Results}

Table 2 summarizes the values of the of estimated overall effect sizes at the $95 \% \mathrm{CI}$ and their statistical significance (at $5 \%$ significance level) computed by all the available models in Stata, i.e., DL, ML, REML, and PL. The results of the DL model overall effect size suggest determinants such as age, membership, and credit had a positive effect on SI adoption. In contrast, arable land and gender had a negative effect on the adoption of SI in SADC (see Table 2). If we look at the $5 \%$ significance level of the $95 \% \mathrm{CI}$, the estimated overall effects of gender and credit were the only valid results across all four models. From the results, we could infer that farmers having access to credit were $1.2\left(e^{0.156}\right)$ times 
more likely to adopt SI compared to those not having access to credit service, while male farmers were less likely $0.6\left(e^{0.509}\right)$ to adopt SI compared to female farmers.

Table 2. Estimated overall effect sizes and their 95\% CIs by DL, ML, REML, PL models.

\begin{tabular}{|c|c|c|c|c|}
\hline Determinants & DL Model & ML Model & REML Model & PL Model \\
\hline & (1) & (2) & (3) & (4) \\
\hline \multirow{4}{*}{ Age } & $0.058^{(1) *(3)}$ & 0.119 & 0.119 & 0.119 \\
\hline & $(0.023,0.092)^{(2)}$ & $(-0.075,0.313)$ & $(-0.079,0.316)$ & $(-0.082,0.319)$ \\
\hline & $(0.069)^{(4)}$ & -0.388 & -0.395 & -0.401 \\
\hline & $-0.203^{*}$ & 0.402 & -0.202 & -0.202 \\
\hline \multirow[t]{3}{*}{ Arable Land } & $(-0.402,-0.004)$ & $(-0.063,0.867)$ & $(-0.66,0.256)$ & $(-0.668,0.266)$ \\
\hline & -0.398 & -0.93 & -0.916 & -0.934 \\
\hline & -0.034 & -0.033 & -0.032 & -0.033 \\
\hline \multirow{3}{*}{ Education } & $(-0.149,0.080)$ & $(-0.44,0.374)$ & $(-0.447,0.383)$ & $(-0.451,0.393)$ \\
\hline & -0.229 & -0.814 & -0.83 & -0.845 \\
\hline & 0.005 & 3 & 0.003 & 0.003 \\
\hline \multirow[t]{3}{*}{ Extension } & $(-0.027,0.036)$ & $(-0.011,0.017)$ & $(-0.012,0.019)$ & $(-0.014,0.020)$ \\
\hline & -0.063 & -0.028 & -0.031 & -0.034 \\
\hline & $-0.503^{*}$ & $-0.509^{*}$ & $-0.507^{*}$ & $-0.509^{*}$ \\
\hline \multirow[t]{3}{*}{ Gender } & $(-0.866,-0.140)$ & $(-0.844,-0.173)$ & $(-0.849,-0.165)$ & $(-0.852,-0.155)$ \\
\hline & -0.726 & -0.671 & -0.684 & -0.697 \\
\hline & -0.07 & -0.079 & -0.078 & -0.079 \\
\hline \multirow[t]{3}{*}{ Household Size } & $(-0.154,0.014)$ & $(-0.278,0.12)$ & $(-0.282,0.125)$ & $(-0.285,0.132)$ \\
\hline & -0.168 & -0.398 & -0.407 & -0.417 \\
\hline & -0.011 & -0.009 & -0.005 & -0.009 \\
\hline \multirow[t]{3}{*}{ Income } & $(-0.186,0.163)$ & $(-0.192,0.175)$ & $(-0.199,0.188)$ & $(-0.200,0.209)$ \\
\hline & -0.349 & -0.367 & -0.387 & -0.409 \\
\hline & $0.398^{*}$ & 0.402 & 0.402 & 0.402 \\
\hline \multirow[t]{3}{*}{ Membership } & $(0.180,0.616)$ & $(-0.063,0.867)$ & $(-0.078,0.882)$ & $(-0.092,0.896)$ \\
\hline & -0.436 & -0.93 & -0.96 & -0.988 \\
\hline & $0.156^{*}$ & $0.159^{*}$ & $0.16^{*}$ & $0.159^{*}$ \\
\hline \multirow[t]{2}{*}{ Credit } & $(0.072,0.241)$ & $(0.043,0.276)$ & $(0.036,0.283)$ & $(0.031,0.290)$ \\
\hline & -0.169 & -0.233 & -0.247 & -0.259 \\
\hline
\end{tabular}

Notes: (1) The estimated overall effect sizes are Log ORs computed by Stata. (2) Width of 95\% CI = lower and upper limit of $95 \%$ CI. (3) * Indicates effect size that this is statistically significant at 5\% significance level. (4) The bold represents the narrowest width of $95 \% \mathrm{CI}$ in the row. Source: Authors.

Since the P-value of a significance test is not available in the ML, REML, or PL model, the range of $95 \%$ CIs was used to test the statistical significance of the result at a 0.05 significance level. The narrower the width of the $95 \% \mathrm{CI}$, the more precise the estimation of the effect size. In this respect, the DL model provided the most precise estimations for seven of the nine determinants namely: age, arable land, education, household size, income, membership, and credit (see Table 2). We took a closer look at the precision level of the determinants in question within the DL model (see Figure 2). The sequence of order from the narrowest to the widest $95 \%$ CI of the estimated overall effect size, assuming a 0.2-point drop mark, was the extension, age, education, household size, credit, income, arable land, membership and gender. This implied that extension had the most precise overall effect size, although not statistically significant, while gender had the least precise result.

To get a good overview of the statistical significance and precision of estimation reported by the DL model, we present the results in Table 3. The estimated overall effect size of membership and credit were highly statistically significant at $0.1 \%$.

In terms of precision, extension, age, education, household size, and credit were the top-five ranked determinants based on a 0.2 threshold. We can interpret from Table 3 that age and credit play a significant role in SI adoption in SADC. That is to say, the estimated overall effect size of age and credit are the only two simultaneously significant and precise computed by the DL model.

Table 4 summarizes the value of $I^{2}$ computed by the DL, ML, REML, and PL model. We interpret the estimates based on the classification above of $I^{2}$ by Higgins and Thompson [33]. The estimated overall effects for all the nine determinants, except for extension for ML, REML, and PL, were considerably heterogeneous across all the models. 


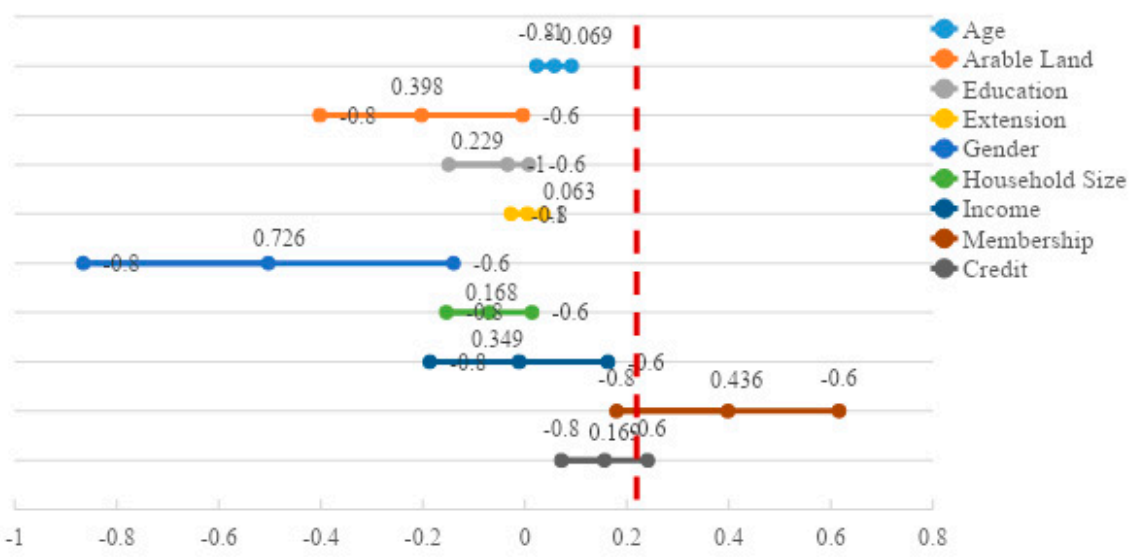

Figure 2. Forest plot to study the distribution of the estimated overall effect sizes computed by the DL Model. Source: Authors.

Table 3. P-values and widths of CIs of estimated overall effect sizes Computed by DL Model.

\begin{tabular}{cccccc}
\hline $\begin{array}{c}\text { Rankings of } \\
\text { Significance }\end{array}$ & Determinants & $\begin{array}{c}\text { P Values for Significance } \\
\text { Test of ES = 0 }\end{array}$ & $\begin{array}{c}\text { Rankings of } \\
\text { Precision (2) }\end{array}$ & $\begin{array}{c}\text { Determinants } \\
\text { Widths of 95\% } \\
\text { CI }{ }^{\text {(3) }}\end{array}$ \\
\hline 1 & Membership & $0.000^{* * *(4)}$ & 1 & Extension & 0.063 \\
2 & Credit & $0.000^{* * *}$ & 2 & Age & 0.069 \\
3 & Age & $0.001^{* *(5)}$ & 3 & Education & 0.157 \\
4 & Gender & $0.007^{* *}$ & 4 & Household Size & 0.168 \\
5 & Arable Land & $0.046^{*}(6)$ & 5 & Credit & 0.169 \\
6 & Household Size & 0.102 & 6 & Income & 0.349 \\
7 & Education & 0.556 & 7 & Arable Land & 0.398 \\
8 & Extension & 0.778 & 8 & Membership & 0.436 \\
9 & Income & 0.900 & 9 & Gender & 0.726 \\
\hline
\end{tabular}

Notes: (1) Rankings of significance: sorted by P-value of significance test (null hypothesis is ES = 0), from the smallest value to the largest value. (2) Rankings of precision: sorted by the width of $95 \% \mathrm{CI}$ of estimated overall effect size, from the smallest value to the largest value. (3) Widths of $95 \%$ CI: calculated by subtracting the lower limit of $95 \%$ CI from the upper limit of $95 \%$ CI. (4) ${ }^{* * *}$ indicates that this effect size is statistically significant at $0.1 \%$ significance level, i.e., P-value $\leqq 0.001$. (5) ${ }^{* *}$ indicates that this effect size is statistically significant at a $1 \%$ significance level but not significant at a $0.1 \%$ significance level, i.e. $0.001<$ P-value $\leqq 0.01$. (6) * indicates that this effect size is statistically significant at a $5 \%$ significance level but not significant above the $5 \%$ significance level, i.e., $0.01 \leqq$ P-value $<0.05$. Source: Authors.

Table 4. $I^{2}$ for estimated overall effect sizes by the DL, ML, REML, PL Model.

\begin{tabular}{ccccc}
\hline Determinants & DL Model & ML Model & REML Model & PL Model \\
\hline & $\mathbf{( 1 )}$ & $\mathbf{( 2 )}$ & $\mathbf{( 3 )}$ & $\mathbf{( 4 )}$ \\
\hline Age & $96.20 \%$ & $99.91 \%$ & $99.91 \%$ & $99.91 \%$ \\
Arable Land & $98.80 \%$ & $99.51 \%$ & $99.97 \%$ & $99.76 \%$ \\
Education & $97.50 \%$ & $99.83 \%$ & $99.83 \%$ & $99.83 \%$ \\
Extension & $80.30 \%$ & $34.45 \%$ & $40.64 \%$ & $34.45 \%$ \\
Gender & $97.90 \%$ & $97.51 \%$ & $97.62 \%$ & $97.51 \%$ \\
Household Size & $94.30 \%$ & $99.07 \%$ & $99.11 \%$ & $99.07 \%$ \\
Income & $76.50 \%$ & $79.03 \%$ & $81.55 \%$ & $79.03 \%$ \\
Membership & $97.40 \%$ & $99.51 \%$ & $99.54 \%$ & $99.51 \%$ \\
Credit & $95.20 \%$ & $97.72 \%$ & $98.00 \%$ & $97.72 \%$ \\
\hline
\end{tabular}

The results from Table 4 imply that we have to conduct a subgroup analysis to eliminate the causes of heterogeneity, i.e., drop outliers. Table 5 shows that after conducting the subgroup analysis, there was substantially lower heterogeneity within the more convergent column compared to that of the less convergent and overall. The low level of heterogeneity means smaller between-study variance and more similar results for the more convergent. For the more convergence, the estimated overall effect size of age, membership and credit displace a relative considerably heterogeneity. In contrast, 
the estimated overall effect sizes of extension, gender, arable land, education, and income range from homogenous to highly heterogeneous.

Table 5. Subgroups analysis classified by effect size using the DL model.

\begin{tabular}{cccc}
\hline Determinants & More Convergent & Less Convergent & Overall \\
\hline Age & $93.10 \%$ & $98.50 \%$ & $96.20 \%$ \\
Arable Land & $70.20 \%(1)$ & $99.60 \%$ & $98.80 \%$ \\
Education & $64.30 \%$ & $99.30 \%$ & $97.50 \%$ \\
Extension & $0.00 \%$ & $82.20 \%$ & $80.30 \%$ \\
Gender & $0.00 \%$ & $98.40 \%$ & $97.90 \%$ \\
Household Size & $50.00 \%$ & $99.00 \%$ & $94.30 \%$ \\
Income & $69.40 \%$ & $75.30 \%$ & $76.50 \%$ \\
Membership & $90.30 \%$ & $99.40 \%$ & $97.40 \%$ \\
Credit & $78.70 \%$ & $96.30 \%$ & $95.20 \%$ \\
\hline
\end{tabular}

Note: (1) Italic indicates not considerably heterogeneous $\left(I^{2}<75 \%\right)$ Source: Authors.

We adopted a $5 \%$ significance level in the significance test and set $I^{2}=75 \%$ as the limit for distinguishing heterogeneity. In other words, only results that are simultaneously statistically significant at a $5 \%$ significance level and have a value of $I^{2}$ less than $75 \%$ were viewed as valid results. In Table 6 , seven of the nine determinants were statistically significant at a $0.1 \%$ and $1 \%$ significance level in the more convergent subgroup. Seven of the nine determinants were statistically significant at a $0.1 \%$ and $1 \%$ significance level in the more convergent subgroup. The results suggest that when the size of arable land increases by one unit, farmers are $1.096\left(e^{0.092}\right)$ times more likely to adopt SI in SADC with similar results for education which is in strong contrast to the results without the subgroup analysis presented in Table 2. Increasing extension, household size, membership of cooperative and access to credit by one unit would likely increase the adoption of SI among farmers in SADC by units greater than 1 . The result of gender was consistent with the results from Table 2 that male farmers were $0.467\left(e^{-0.762}\right)$ less likely to adopt SI compared female farmers.

Table 6. Estimated effect sizes in subgroups by the DL Model, classified by effect size.

\begin{tabular}{cccc}
\hline Determinants & More Convergent & Less Convergent & Overall \\
\hline \multirow{2}{*}{ Age } & 0.022 & 0.442 & $0.058^{* *}$ \\
& $(-0.002,0.046)$ & $(-0.447,1.331)$ & $(0.023,0.092)$ \\
& $(\mathrm{n}=25)^{(1)}$ & $(\mathrm{n}=8)$ & $(\mathrm{n}=33)$ \\
Arable Land & $0.092^{* * *(2)}$ & -1.233 & $-0.203^{*}$ \\
& $(0.048,0.135)$ & $(-3.416,0.949)$ & $(-0.402,-0.004)$ \\
& $(\mathrm{n}=18)$ & $(\mathrm{n}=5)$ & $(\mathrm{n}=23)$ \\
Education & $0.083^{* * *}$ & -0.139 & -0.034 \\
& $(0.051,0.115)$ & $(-2.084,1.806)$ & $(-0.149,0.080)$ \\
Extension & $(\mathrm{n}=21)$ & $(\mathrm{n}=8)$ & $(\mathrm{n}=29)$ \\
& $0.013^{* *(3)}$ & 0.038 & 0.005 \\
& $(0.003,0.02)$ & $(-0.107,0.183)$ & $(-0.027,0.036)$ \\
Gender & $(\mathrm{n}=5)$ & $(\mathrm{n}=15)$ & $(\mathrm{n}=20)$ \\
& $-0.762^{* * *}$ & -0.404 & $-0.503^{* *}$ \\
& $(-0.915,-0.609)$ & $(-0.867,0.058)$ & $(-0.866,-0.140)$ \\
Household Size & $(\mathrm{n}=7)$ & $(\mathrm{n}=18)$ & $(\mathrm{n}=25)$ \\
& $0.053^{* * *}$ & -0.446 & -0.07 \\
& $(0.022,0.084)$ & $(-1.297,0.406)$ & $(-0.154,0.014)$ \\
Income & $(\mathrm{n}=22)$ & $(\mathrm{n}=5)$ & $(\mathrm{n}=27)$ \\
& -0.022 & 0.005 & -0.011 \\
& $(-0.235,0.191)$ & $(-0.232,0.241)$ & $(-0.186,0.163)$ \\
Membership & $(\mathrm{n}=2)$ & $(\mathrm{n}=13)$ & $(\mathrm{n}=15)$ \\
& $0.215^{* *}$ & 0.69 & $0.398^{* * *}$ \\
& $(0.081,0.348)$ & $(-1.540 .2 .919)$ & $(0.180,0.616)$ \\
& $(\mathrm{n}=12)$ & $(\mathrm{n}=4)$ & $(\mathrm{n}=16)$ \\
& $0.188^{* *}$ & $0.136^{*(4)}$ & $0.156^{* * *}$ \\
& $(0.054,0.321)$ & $(0.030,0.243)$ & $(\mathrm{n}=16)$ \\
\hline & $(\mathrm{n}=12)$ & $(\mathrm{n}=4)$ & $(0.072,0.241)$ \\
& & &
\end{tabular}

Notes: (1) $n$ indicates the number of included primary study results. (2) ${ }^{* *}$ indicates that this effect size is statistically significant at a $0.1 \%$ significance level, i.e. P-value $\leqq 0.001$. (3) ${ }^{* *}$ indicates that this effect size is statistically significant at a $1 \%$ significance level but not significant at a $0.1 \%$ significance level, i.e. $0.001<\mathrm{P}$-value $\leqq 0.01$. (4) * indicates that this effect size is statistically significant at a 5\% significance level but not significant above the $5 \%$ significance level, i.e., $0.01 \leqq$ P-value $<0.05$. Source: Authors. 


\section{Discussion}

This study set out to analyze the true effect size of identified determinants of SI adoption among smallholder farmers in SADC considering their vulnerability to climate change. These determinants included age, size of arable land, education, extension, gender, household size, income, membership in a farming organization, and access to credit. Given that there is often no clear direction of the magnitude of some of the determinants, we reverted to a comprehensive meta-analysis in this study. We estimated the effect size of the determinants above using random-effect models, specifically the DL model, ML model, REML model, and the PL model using a standardization approach. The DL model produced a high degree of statistically significant and precise results, which, to some extent, aligned with conventional findings, as well as others that were not necessarily plausible. For instance, in our study age, membership and credit were found to have a positive and significant effect size on the adoption of certain SI practices among smallholder farmers in SADC similar to the study by Zulu-Mbata et al. [47]. Conversely, the study by Manda et al. [48] was inconclusive on the effect of membership in a farming organization on SI adoption. Meanwhile, education and extension were positive and significant, which aligned with the study of Mavunganidze et al. [49]. However, some of the results of these previous studies appear not to align with our meta-analysis, at least at the initial stage, as it suggests that education and extension provide insignificant and negative values as effect size. Furthermore, our initial results of the effect size suggest that female smallholders are more likely to adopt SI compared to their male counterparts in SADC. This result contradicts the study by Manda et al. [48] who argue that women are resource-constrained and do not have access to adequate extension services. However, one could also counter-argue that while male smallholders probably own the asset, the running of the day-to-day agricultural land activities in SSA remains in the hands of female smallholders [50], which would also hold for the SADC region. Our somewhat unconventional results of the overall effect sizes of some of the determinants of SI adoption among smallholder farmers requires further analysis on the precision of these determinants and their similarity across the different studies aside from the atypical statistical significance. We conclude that only access to credit and age can be ascertained to have produced valid results, given their significance and precision, from our initial stage meta-analysis. Our results from the initial stage meta-analysis can, however, be considered invalid according to the heterogeneity, i.e., between-study variance analysis as none of the determinants across all models were in the ranges low to high, in other words $I^{2}<75 \%$. To reduce heterogeneity in our dataset to an acceptable level, we conducted a subgroup analysis resulting in two groups, i.e., more and less convergent. In the more convergent category, several determinants namely; arable land, education, extension, gender, household size and income had $I^{2}<75 \%$ with credit a little above this threshold. Given that the DL model reports statistical significance and is the most precise of all the models, another round of meta-analysis was conducted using this model. The results suggest that the effect size of arable land, education, extension, household size and credit are positive and statistically significant, while gender remains negative and also significant. These results have some immense implications for the spread of SI practices in SADC. While there are a number of large farms operational in the SADC which may help adoption of SI practices, micro- and small scale farming systems are prevalent and shape the agricultural landscape. Some of these farmers have limited or no education or access to credit [16]. This could explain the modest uptake of the SI, especially among smallholder farmers. Our result strongly suggests that women smallholders are more likely to adopt SI practices compared to their male counterparts in SADC. This may be due to the aforementioned line of reasoning that women often actively partake in on-farm activities in SSA, and our results align with results from other studies [51,52]. A major limitation of the meta-analysis of the adoption of agriculture innovations, e.g., SI and its impact on food security in developing countries, is its inability to account for vital qualitative dimensions and their interactions adequately. For instance, certain variables under consideration in this study, e.g., extension services and credit do not consider the fit-for-purpose solutions for farmers based on the complexity of the SI options and the influence of social capital $[16,53,54]$. 


\section{Conclusions}

This study set out to answers to the question: What are the essential drivers or determinants of SI in SSA sub-regions most vulnerable to climate change such as the SADC? Our meta-analysis shows that arable land size, education, extension, household size and access to credit are key to the adoption of SI by smallholder farmers in the SADC. Meanwhile, the role that women smallholder farmers play in SI adoption remains unquestionable. Thus, policymakers in the SADC economic block, especially those located in vulnerable regions that would like to promote SI adoption among smallholder farmers, should further develop some of these variables. This could take the form of turning small fragmented parcel of lands into a larger farm through a more proactive farmer's association. Smallholder farmers affected by climate change participating in such associations can also acquire new skills and techniques related to SI practices through farmer schools, demonstration farms, etc. Meanwhile, adequate provision should be made for the content-specific public, as well as private extension services. There is also a need to develop novel models for sustainable agricultural financing for smallholder agribusiness adopting SI practices [53] given the prevalence of credit rationing to overall agricultural systems in SSA. This should involve the participation of different stakeholders ranging from private financial institutions to agricultural development intervention programs. The role of women should be taken more seriously in the spread of SI in the SADC region. There should be awareness campaigns to showcase some of the benefits that accrue to women smallholders who adopt some form of SI practices which, according to Benjamin et al. [17], includes economic empowerment. Finally, there is a need for further research using meta-analysis to assess the true effect of the determinants of SI in SADC by expanding such studies based on a more comprehensive climatic classification, an improved methodology of estimation, as well as the inclusion of future studies.

Author Contributions: Conceptualization, Q.G. and E.O.B.; Methodology, Q.G. and E.O.B.; Software, Q.G. and E.O.B.; Validation, O.O. and E.O.B.; Formal Analysis, Q.G. and E.O.B.; Investigation, Q.G. and E.O.B.; Data Curation, Q.G.; Writing - Original Draft Preparation, Q.G. and E.O.B.; Writing - Review \& Editing, O.O.; Supervision, E.O.B.. All authors have read and agreed to the published version of the manuscript.

Funding: This research received no external funding.

Conflicts of Interest: The authors declare no conflict of interest.

\section{References}

1. Tilman, D.; Balzer, C.; Hill, J.; Befort, B.L. Global food demand and the sustainable intensification of agriculture. PNAS 2011, 108, 20260-20264. [CrossRef] [PubMed]

2. Pardey, P.G.; Beddow, J.M.; Hurley, T.M.; Beatty, T.K.; Eidman, V.R. A bounds analysis of world food futures: Global agriculture through to 2050. Aust. J. Agric. Resour. Econ. 2014, 58, 571-589. [CrossRef]

3. Godfray, H.C.J.; Beddington, J.R.; Crute, I.R.; Haddad, L.; Lawrence, D.; Muir, J.F.; Pretty, J.; Robinson, S.; Thomas, S.M.; Toulmin, C. Food security: The challenge of feeding 9 billion people. Science 2010, 327, 812-818. [CrossRef] [PubMed]

4. Vermeulen, S.J.; Campbell, B.M.; Ingram, J.S. Climate change and food systems. Annu. Rev. Env. Resour. 2012, 37, 195-222. [CrossRef]

5. The Montpellier Panel. Sustainable Intensification: A New Paradigm for African Agriculture. 2013. Available online: https://europa.eu/capacity4dev/hunger-foodsecurity-nutrition/document/sustainable-intensificationnew-paradigm-african-agriculture (accessed on 20 March 2019).

6. Garnett, T.; Appleby, M.C.; Balmford, A.; Bateman, I.J.; Benton, T.G.; Bloomer, P.; Burlingame, B.; Dawkins, M.; Dolan, L.; Fraser, D.; et al. Sustainable intensification in agriculture: Premises and policies. Science 2013, 341, 33-34. [CrossRef] [PubMed]

7. D'Souza, G.; Cyphers, D.; Phipps, T. Factors affecting the adoption of sustainable agricultural practices. Agric. Econ. Res. Rev. 1993, 22, 159-165. [CrossRef]

8. Lee, D.R. Agricultural Sustainability and Technology Adoption: Issues and Policies for Developing Countries. Am. J. Agric. Econ. 2005, 87, 1325-1334. [CrossRef] 
9. Pretty, J.; Toulmin, C.; Williams, S. Sustainable intensification in African agriculture. Int. J. Agr. Sustain. 2011, 9, 5-24. [CrossRef]

10. Vanlauwe, B.; Coyne, D.; Gockowski, J.; Hauser, S.; Huising, J.; Masso, C.; Nziguheba, G.; Schut, M.; Van Asten, P. Sustainable intensification and the African smallholder farmer. Curr. Opin. Env. Sust. 2014, 8, 15-22. [CrossRef]

11. Holden, S.T. Fertilizer and sustainable intensification in Sub-Saharan Africa. Glob. Food Security 2018, 18, 20-26. [CrossRef]

12. Pretty, J.; Bharucha, Z.P. Sustainable intensification in agricultural systems. Ann. Bot. 2014, 114, 1571-1596. [CrossRef] [PubMed]

13. Giller, K.E.; Andersson, J.A.; Corbeels, M.; Kirkegaard, J.; Mortensen, D.; Erenstein, O.; Vanlauwe, B. Beyond conservation agriculture. Front. Plant Sci. 2015, 6, 870. [CrossRef] [PubMed]

14. Kassie, M.; Zikhali, P.; Pender, J.; Köhlin, G. The economics of sustainable land management practices in the Ethiopian highlands. J. Agric. Econ. 2010, 61, 605-627. [CrossRef]

15. Mango, N.; Siziba, S.; Makate, C. The impact of adoption of conservation agriculture on smallholder farmers' food security in semi-arid zones of southern Africa. Agric. Food Secur. 2017, 6, 32. [CrossRef]

16. Benjamin, E.O.; Blum, M.; Punt, M. The impact of extension and ecosystem services on smallholder's credit constraint. J. Dev. Areas 2016, 50, 333-350. [CrossRef]

17. Benjamin, E.O.; Ola, O.; Buchenrieder, G. Does an agroforestry scheme with payment for ecosystem services (PES) economically empower women in sub-Saharan Africa? Ecosyst. Serv. 2018, 31, 1-11. [CrossRef]

18. Benjamin, E.O.; Sauer, J. The cost effectiveness of payments for ecosystem services—Smallholders and agroforestry in Africa. Land Use Policy 2018, 71, 293-302. [CrossRef]

19. Teklewold, H.; Kassie, M.; Shiferaw, B. Adoption of multiple sustainable agricultural practices in rural Ethiopia. J. Agric. Econ. 2013, 64, 597-623. [CrossRef]

20. Firbank, L.G.; Attwood, S.; Eory, V.; Gadanakis, Y.; Lynch, J.M.; Sonnino, R.; Takahashi, T. Grand challenges in Sustainable intensification and ecosystem Services. Front. Sustain. Food Syst. 2018, 2, 7. [CrossRef]

21. Gadanakis, Y.; Bennett, R.; Park, J.; Areal, F.J. Evaluating the sustainable intensification of arable farms. J. Environ. Manag. 2015, 150, 288-298. [CrossRef]

22. Garnett, T.; Godfray, C. Sustainable Intensification in Agriculture: Navigating a Course through Competing Food System Priorities; Food Climate Research Network and the Oxford Martin Programme on the Future of Food; Oxford Martin School: Oxford, UK, 2012; pp. 6-51.

23. Moran, D.; Lucas, A.; Barnes, A. Mitigation win-win. Nat. Clim. Change 2013, 3, 611-613. [CrossRef]

24. Shiferaw, B.; Tesfaye, K.; Kassie, M.; Abate, T.; Prasanna, B.M.; Menkir, A. Managing vulnerability to drought and enhancing livelihood resilience in sub-Saharan Africa: Technological, institutional and policy options. Weather Clim. Extremes 2014, 3, 67-79. [CrossRef]

25. Nhemachena, C.; Hassan, R. Micro-Level Analysis of Farmer's Adaption to Climate Change in Southern Africa; International Food Policy Research Institute: Washington, DC, USA, 2007; pp. 1-29.

26. Cooper, H.M. Scientific guidelines for conducting integrative research reviews. Rev. Educ. Res. 1982, 52, 291-302. [CrossRef]

27. Martin, K.G. The Difference between Logistic and Probit Regression. 2008. Available online: https://www. theanalysisfactor.com/the-difference-between-logistic-and-probit-regression/ (accessed on 1 March 2019).

28. Kelley, G.A.; Kelley, K.S. Statistical models for meta-analysis: A brief tutorial. World J. Methodol. 2012,2 , 27. [CrossRef]

29. Ialongo, C. Understanding the effect size and its measures. Biochem. Med. 2016, 26, 150-163. [CrossRef]

30. Borenstein, M.; Hedges, L.; Rothstein, H. Meta-Analysis: Fixed Effect vs. Random Effects. 2007. Available online: www.meta-analysis.com (accessed on 5 February 2019).

31. Thompson, S.G.; Pocock, S.J. Can meta-analyses be trusted? Lancet 1991, 338, 1127-1130. [CrossRef]

32. Veroniki, A.A.; Jackson, D.; Viechtbauer, W.; Bender, R.; Bowden, J.; Knapp, G.; Kuss, O.; Higgins, J.P.; Langan, D.; Salanti, G. Methods to estimate the between-study variance and its uncertainty in meta-analysis. Res. Synth. Methods 2015, 7, 55-79. [CrossRef]

33. Higgins, J.P.; Thompson, S. Quantifying Heterogeneity in a Meta-analysis. Stat. Med. 2002, 21, 1539-1558. [CrossRef] 
34. Higgins, J.P.T.; Green, S. Cochrane Handbook for Systematic Reviews of Interventions. 2011. Available online: https://handbook-5-1.cochrane.org/chapter_12/12_4_1_confidence_intervals.htm (accessed on 5 February 2019).

35. Knapp, G.; Biggerstaff, B.; Hartung, J. Assessing the amount of heterogeneity in random-effects meta-analysis. Biom. J. 2006, 48, 271-285. [CrossRef]

36. Viechtbauer, W. Bias and efficiency of meta-analytic variance estimators in the random-effects model. J. Educ. Behav. Stat. 2005, 30, 261-293. [CrossRef]

37. Novianti, P.W.; Rose, K.C.B.; van der Tweel, I. Estimation of between-trial variance in sequential meta-analyses: A simulation study. Contemp. Clin. Trials 2014, 37, 129-138. [CrossRef]

38. Sidik, K.; Jonkman, J.N. A comparison of heterogeneity variance estimators in combining results of studies. Stat. Med. 2007, 26, 1964-1981.

39. Altman, D.G.; Bland, J.M. How to obtain the confidence interval from a P value. Br. Med. J. 2011, 343 , d2090. [CrossRef]

40. Altman, D.G.; Bland, J.M. How to obtain the P value from a confidence interval. Br. Med. J. 2011, 343, d2304. [CrossRef]

41. Du Prel, J.B.; Hommel, G.; Röhrig, B.; Blettner, M. Confidence interval or p-value? Part 4 of a series on evaluation of scientific publications. Dtsch. Arztebl. Int. 2009, 106, 335-339. [CrossRef]

42. LaMorte, W.W. Confidence Intervals and P-Values. 2016. Available online: http://sphweb.bumc.bu.edu/otlt/ MPHModules/EP/EP713_RandomError/EP713_RandomError6.html (accessed on 15 February 2019).

43. Ryan, R. Heterogeneity and Subgroup Analysis in Cochrane Consumers and Communication Group Reviews: Planning the Analysis at Protocol Stage. 2016. Available online: https://cccrg.cochrane.org (accessed on 18 February 2019).

44. Ngwira, A.; Johnsen, F.H.; Aune, J.B.; Mekuria, M.; Thierfelder, C. Adoption and extent of conservation agriculture practices among smallholder farmers in Malawi. J. Soil Water Conserv. 2014, 69, 107-119. [CrossRef]

45. Chompolola, A.; Kaonga, O. Adoption of conservation agriculture in Zambia-The case of Chongwe District. J. Sustain. Dev. 2016, 9, 77-86. [CrossRef]

46. Huedo-Medina, T.B.; Sanschez-Meca, J.; Marin-Martinez, F.; Botella, J. Assessing heterogeneity in Meta-analysis: Q statistics or I squared index? Psychol. Methods 2006, 11, 193-206. [CrossRef]

47. Zulu-Mbata, O.; Chapoto, A.; Hichaambwa, M. Determinants of Conservation Agriculture Adoption among Zambian Smallholder Farmers; IAPRI Working Papers; Indaba Agricultural Policy Research Institute: Lusaka, Zambia, 2016.

48. Manda, J.; Alene, A.D.; Gardebroek, C.; Kassie, M.; Tembo, G. Adoption and impacts of sustainable agricultural practices on maize yields and incomes: Evidence from rural Zambia. J. Agric. Econ. 2016, 67, 130-153. [CrossRef]

49. Mavunganidze, Z.; Madakadze, J.C.; Mutenje, M.J.; Nyamangara, J. Factors affecting the choice of conservation agriculture practices adopted by smallholder cotton farmers in Zimbabwe. Afr. J. Agric. Res. 2013, 8, 1641-1649.

50. Bryson, J.C. Women and agriculture in sub-Saharan Africa: Implications for development (an exploratory study). J. Dev. Stud. 1981, 17, 29-46. [CrossRef]

51. Raney, T.; Anríquez, G.; Croppenstedt, A.; Gerosa, S.; Lowder, S.K.; Matuschke, I.; Skoet, J.; Doss, C. The Role of Women in Agriculture. 2011. Available online: http://www.fao.org/3/a-am307e.pdf (accessed on 15 March 2019).

52. Saito, K.A.; Mekonnen, H.; Spurling, D. Raising the Productivity of Women Farmers in Sub-Saharan Africa; The World Bank: Washington, DC, USA, 1994; pp. 1-118.

53. Benjamin, E.O. Adverse selections and microfinance in rural Africa: Signalling through environmental services. Enterp. Dev. Microfinance 2013, 24, 28-39. [CrossRef]

54. Benjamin, E.O.; Blum, M. Participation of smallholders in agrofoestry agri-environmental scheme: A lesson from the rural mount Kenyan region. J. Dev. Areas 2015, 49, 127-143. [CrossRef]

(C) 2020 by the authors. Licensee MDPI, Basel, Switzerland. This article is an open access article distributed under the terms and conditions of the Creative Commons Attribution (CC BY) license (http://creativecommons.org/licenses/by/4.0/). 